\title{
Examining the Characteristics of Heterogeneous Traffic at Various Lane Closures
}

\author{
Jebaselwin Gladson', Kalaanidhi Sivagnanasundaram², Karthiga Kasi', \\ Gunasekaran Karuppanan* \\ ${ }^{1}$ Division of Transportation Engineering, Anna University, Kotturpuram, Chennai, 600025 Tamil Nadu, India \\ 2 Department of Civil Engineering, National Institute of Technology Karnataka, \\ Srinivas nagar, Surathkal, Mangalore, 575025 Karnataka, India \\ *Corresponding author, e-mail: kgunasekaran@annauniv.edu
}

Received: 04 November 2019, Accepted: 03 December 2019, Published online: 09 April 2020

\begin{abstract}
The primary aim of this study is to support the policy decisions on selection of a work zone layout that would have least deterrence to the traffic flow on busy urban arterials carrying heterogeneous traffic. The traffic flow characteristics were recorded with two cameras and the speed variation was obtained by plying probe vehicles fitted with Global Positioning Systems (GPSs) repeatedly in the section. The traffic stream speed and capacity of the various types of work zone sections were analyzed and it is found that near side lane closure has a relatively least effect on capacity (15\%) whereas the effect of run around type closure is maximum (46 \%). The reasons for the variations in speed and capacity at these types of work zones were examined and reported. Besides, the application of the study results with respect to planning of work zone layout is discussed.
\end{abstract}

Keywords

work zone, urban roads, capacity, probe vehicles, heterogeneous traffic

\section{Introduction}

In large cities, the rise in travel demand and more dependability on personalized vehicles have led to the severe congestion and delay. The construction of transport infrastructures like metro rail, Bus Rapid Transit System (BRTS), monorail corridors, and grade separators is in progress in many cities to ease the congestion level. In such places, work zones are, therefore, required to segregate the work areas for safety of men and material, and also to facilitate safe movement of road users. In order to facilitate the construction activities, lane closures are inevitable; which will exist either for short term or long term, based on the type of the infrastructure built. These lane closures are classified based on the type of lane closures such as Near Side Lane Closure (NSLC), Far Side Lane Closure (FSLC), Middle Lane Closure (MLC), RunAround (RA) and Cross-Over (CO). Selection of particular type of lane closure depends on the site configuration and the merits and demerits associated with each type of lane closures. The economic loss due to delayed traffic flow for each type of lane closures, if it is to exist for longer duration, is to be quantified exactly for planning work zone layouts. In addition to the economic perspective, the impact of the various types of lane closures over the traffic is essentially to be quantified for the formulation of effective traffic management strategies in urban areas.

Impacts of lane closures are, in general, measured with respect to the increase in travel time for the road users and capacity reduction of the road. Design and traffic control features of the work zones influence the speed of the vehicles at the work zone (Porter and Wood, 2013). Stream speed of the vehicles passing through work zone is a key parameter to understand the impact of work zone on traffic flow. The speed of traffic at work zones was measured from the video graphic records (Maze et al., 2000; Vidya et al., 2012; Elangovan et al., 2015). Congestion of the traffic because of the construction work zone was measured with the help of two video cameras, one to measure the speed at lane closure zone and another to capture the queue length and speed of the vehicles was plotted against flow rate (Maze et al., 2000) to understand the effect of traffic queue on the vehicle speed. Probe techniques were also deployed for speed measurements. GPS fitted probe 
vehicles were used for measuring speed at the work zones (Elangovan et al., 2015; Jiang and Li, 2001) and travel time along a link road (Sanuallah et al., 2013). Also, blue-tooth probe technique was deployed (Wasson et al., 2008) for measuring the traffic delay. An important observation with respect to measuring speed at work zones is that, as an effect of introduction of construction work zone, the average speed of the vehicles was dropped nearly by $60 \%$ at the transition zone than at the advance warning zone, on a rural highway (Maze et al., 2000). Hence it is important to carefully consider the zone of speed measurement for the analysis of work zone impacts on traffic flow.

The pioneer model for highway capacity estimation, Greenshields model (Greenshields, 1935), is a single regime model which considers the different traffic states together where as the concept of multi regime models advocate constructing separate models for different traffic states.

Instead, Van Aerde's model (Van Aerde, 1995) is also a single regime traffic stream model, which integrates the two models, viz., Greenshields (1935), and Pipes models (1953), to establish the relationship between speed flow and density. The advantage of the Van Aerde's model is that it overcomes the shortcomings of Pipes model by assuming that vehicle speeds are insensitive to traffic density in an uncongested regime; overcomes the main shortcoming of the Greenshields model, which assumes that the speed-flow relationship is parabolic (Rakha, 2009). Alternatively, analytical methods to estimate the capacity of road sections at work zones were also proposed (Maze et al., 2000; Heaslip et al., 2011; Knoop et al., 2009).

However, majority of the earlier studies reporting the impacts of work zones on traffic flow, are pertinent to homogeneous traffic, i.e., car only traffic. In the absence of guidelines for the selection of suitable type of lane closures especially under heterogeneous traffic, in this study, attempt has been made to study the heterogeneous traffic flow characteristics, lane selection of vehicles on conventional urban road sections, and the speed and capacity variations at different types of lane closures viz., Near Side Lane Closure (NSLC), Far Side Lane Closure (FSLC), Middle Lane Closure (MLC) and Run-Around (RA). This study reports the detailed study of afore- mentioned lane closure types and quantification of their impacts in terms of speed and capacity. The information on reduction of stream speed and capacity of the road section at work zones would be used to decide the suitable layout of work zones and to devise optimal traffic management measures at the location.

\section{Methodology}

Four types of work zones were considered in this study. Speed of the traffic flow at the work zone section and queue identification was done with video graphic records and GPS data was collected to analyze speed variation at the work zone sections. The traffic flow was expressed in Passenger Car Equivalences (PCEs). Speed reductions at the work zones were quantified with the GPS data and capacity of the sections were estimated by Van Aerde's method (Van Aerde and Rakha, 1995) and Maze's method (Maze et al., 2000).

\subsection{Study sections}

Metro rail facility is planned and being constructed along two corridors for a length of $45 \mathrm{~km}$ in Chennai city. For this study, totally 5 sections were considered (Fig. 1). A section on Rajiv Gandhi road was chosen as conventional section (location A) to understand the traffic flow on normal road sections and at advance warning zone i.e., section ahead of work zone. The selected road stretch is straight, free from side frictions and on plain terrain. It is a six-lane divided arterial connecting the southern part of the Chennai city with its suburbs.

Four work zones with different configurations viz., FSLC (location B), NSLC (location C), MLC (location D) and RA (location E) located on Grand Southern Trunk (GST) road in Chennai were selected. GST road is a six-lane divided arterial in south western part of Chennai. Due to the Metro rail construction work the carriageway width at location $\mathrm{B}$ and $\mathrm{C}$ were reduced from three lanes to two lanes in one direction of traffic flow. The length of road segment at location B, i.e., between Pallavaram Intersection and

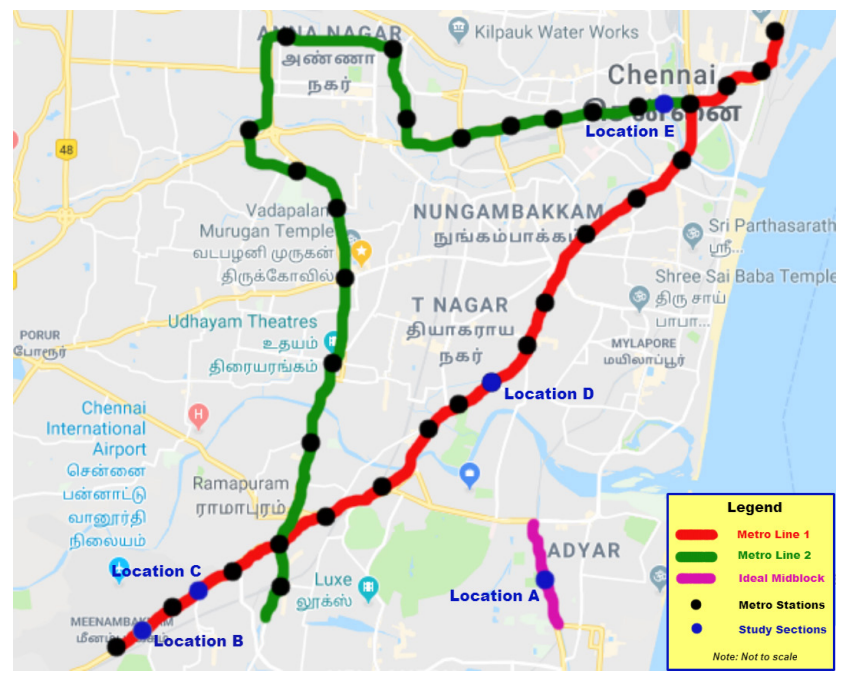

Fig. 1 Metro rail corridor and locations of study sections 
Cargo Intersection, was $3.3 \mathrm{~km}$ whereas at location C, i.e., between Cargo Intersection and Nanganallur Intersection, was $1.3 \mathrm{~km}$. The length of work zones at location $\mathrm{B}$ and $\mathrm{C}$ were $0.4 \mathrm{~km}$ and $1.0 \mathrm{~km}$ respectively. The typical layouts of selected work zone types are shown in Fig. 2. In case of MLC, i.e., location D, the middle lane was restrained for work zone activities and the traffic was allowed on both sides of the work zone through near side and far side lanes. The length of segment in location D was $0.7 \mathrm{~km}$ out of which $0.3 \mathrm{~km}$ was utilized for work zone. In RA (location E), the entire road was earmarked as work zone and the entire traffic flow was diverted to take a small detour to get back to its actual path. Here, the length of the segment was $0.512 \mathrm{~km}$ in which work zone length was $0.475 \mathrm{~km}$.

\subsection{Data collection}

The road section was subdivided as work zone (where the carriageway width was reduced or the alignment was temporarily modified), transition zone (where the reduction in carriageway width was introduced), and advance warning zone (where the traffic is warned about the carriageway reduction). Work zone configuration normally differs from the basic road sections in terms of number of available lanes and diversion arrangements through the work zones. Traffic flow and speed data were collected with video graphic cameras and running GPS fitted probe vehicles repeatedly on the study sections.

Two cameras were located to record the traffic at work zones, camera 1 focusing the traffic flow in transition zone and camera 2 focusing the traffic flow in the work zone section, i.e., at the reduced carriageway portion (Fig. 3). The camera 1 was to identify the time of queuing at the work zone section and traffic data obtained from camera 2 was used for constructing fundamental traffic flow relationships.

The traffic flow and speed information were extracted manually with the aid of indigenous software developed for video extraction purpose. The software helped to obtain lane wise classified vehicle count and speed of the vehicles traversing the defined measurement section $(30 \mathrm{~m}$ length). Video graphic survey was conducted for a period of 4 hours in the morning, covering the peak hour traffic flow at the chosen work zones.

Five cars fitted with GPS units were run repeatedly along the sections to record the speed, travel time and stopped delay of the vehicles. The GPS data was transferred to the servers through GPRS technique. The probe vehicles were plied for 4 hours from 8:00 hrs to $12: 00 \mathrm{hrs}$ and totally 88, 198, 129 and 185 runs were performed with
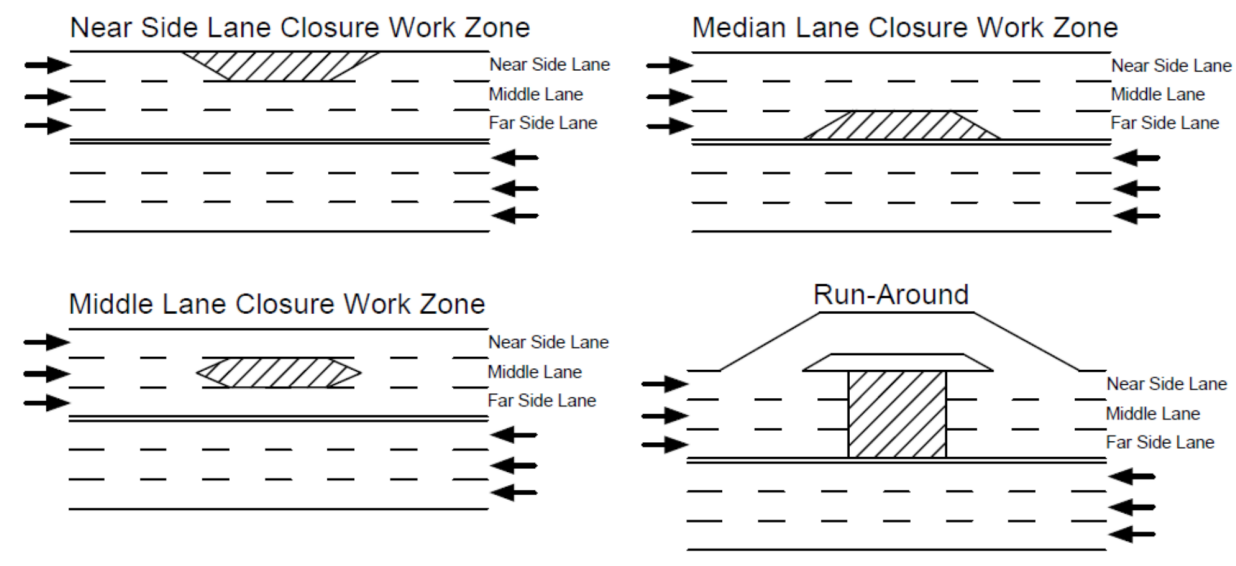

Fig. 2 Selected work zone types

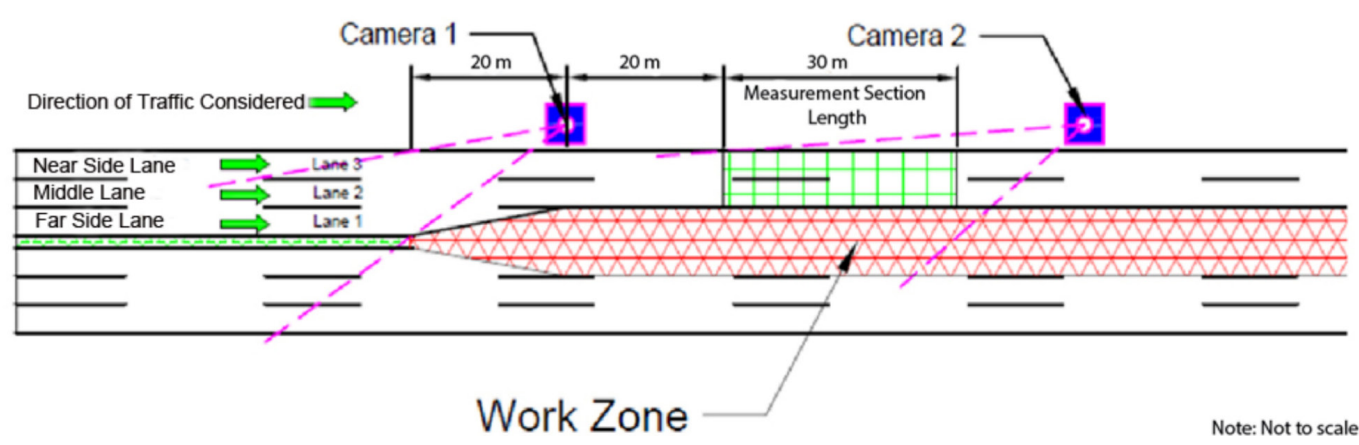

Fig. 3 Arrangement of video graphic cameras 
the test cars at location $\mathrm{B}, \mathrm{C}, \mathrm{D}$ and $\mathrm{E}$ respectively in the observation period. The number of runs performed varied as these section length and traffic congestion level varied at the sections.

\subsection{Estimation of Passenger Car Equivalents (PCEs)}

The traffic flow in India is heterogeneous in nature and PCE values were estimated by dynamic PCE method (Chandra et al., 1995). According to Chandra, PCE of a vehicle depends on the ratio of speed and area of the subject vehicle to that of car. The formula used to calculate PCE value of vehicle $i, \mathrm{PCE}_{i}$ is given as Eq. (1). The average dynamic PCE values were presented in Table 1.

$$
\mathrm{PCE}_{i}=\left(V_{c} / V_{i}\right) /\left(A_{c} / A_{i}\right),
$$

where $V_{c}$ mean speed of the cars in the stream, $V_{i}$ mean speed of the vehicle $i$ in the stream, $A_{c}$ plan area of car, $A_{i}$ plan area of the vehicle.

\subsection{Capacity estimation at work zone sections}

Capacity at the work zones was estimated by Van Aerde's method (Van Aerde and Rakha, 1995) and Maze's method (Maze et al., 2000). Procedures of the two methods are discussed below.

\subsubsection{Van Aerde's method}

The calibration of Van Aerde's model (Van Aerde and Rakha, 1995) requires four parameters $c_{1}, c_{2}, c_{3}$ and $\hat{k}$ hich are related to free flow speed $\left(V_{f}\right)$, Speed at capacity $\left(V_{c}\right)$, jam density $\left(K_{j}\right)$ and capacity $(Q)$ respectively. The Eqs. (2), (3), (4) and (5) were used for calculating the four parameters $c_{1}, c_{2}, c_{3}$ and $\hat{k}$. For every combination of these four parameters, squared orthogonal error (Eq. (9)) was calculated with the field observed data set and, a single combination that produced the minimum squared orthogonal error, was used to develop fundamental relationship.

\begin{tabular}{llc}
\multicolumn{3}{c}{ Table 1 Estimated average dynamic PCE values } \\
\hline Sl. No. & Vehicle Types & PCE Value \\
\hline 1 & Auto Rickshaws & 0.92 \\
2 & Cars & 1.00 \\
3 & Buses & 4.93 \\
4 & Light Commercial Vehicles & 1.11 \\
5 & Motorized Two Wheelers & 0.20 \\
6 & HCV & 3.93 \\
7 & Bicycles & 0.27 \\
8 & Cycle Rickshaws & 1.48 \\
\hline
\end{tabular}

$$
\hat{K}=\frac{1}{c_{1}+\frac{c_{2}}{v_{f}-v}+\left(c_{3} * v\right)}
$$

$c_{1}=m^{*} c_{2}$

$c_{2}=\frac{1}{k_{j}\left(m+\frac{1}{v_{f}}\right)}$

$c_{3}=\frac{-c_{1}+\frac{v_{c}}{q_{c}}-\frac{c_{2}}{v_{f}-v_{c}}}{v_{c}}$

$m=\frac{2 v_{c}-v_{f}}{\left(v_{f}-v_{c}\right)^{2}}$

The constant $m$ was calculated by Eq. (6):

$Q=K^{*} V$

Using the basic traffic stream relationship presented in Eq. (7), the expression for flow in the Van Aerde's model (Van Aerde and Rakha, 1995) becomes:

$\hat{Q}=\frac{v}{c_{1}+\frac{c_{2}}{v_{f}-v}+\left(c_{3} * v\right)}$
Error $=\Sigma\left(\frac{V-\hat{V}}{\tilde{V}}\right)^{2}+\Sigma\left(\frac{Q-\hat{Q}}{\tilde{Q}}\right)^{2}+\Sigma\left(\frac{K-\hat{K}}{\tilde{K}}\right)^{2}$.

where,

$c_{1}=$ Fixed distance headway constant $(\mathrm{km})$

$c_{2}=$ First variable distance headway constant $(\mathrm{km} / \mathrm{h})$

$c_{3}=$ Second variable distance headway constant $(\mathrm{h})$

$m=$ Constant used to solve three headway constants $(\mathrm{h} / \mathrm{km})$

$E=$ Estimated error

$V, Q$ and $K=$ Observed speed, flow and density

$\hat{V}, \hat{Q}$ and $\hat{K}=$ Estimated speed, flow and density

$\tilde{V}, \tilde{Q}$ and $\tilde{K}=$ Mean of observed speed, flow and density

The initial boundary values of the four parameters, based on the recorded range of values, were given as input. In the iterative process, applying the hill climbing technique, the values for the four parameters were gradually increased from the minimum to the maximum boundary values, to determine the global minimum error out of all error values obtained for each combination of parameter values. 


\subsubsection{Maze's method}

Maze et al. (2000) suggested plotting the stream speeds of the vehicles against the flow rate to identify the queuing condition. It was proposed that the capacity of the work zones was the average of ten highest volumes of five minutes aggregated traffic flow rate, observed in the field before and after queuing.

\section{Traffic flow characteristics}

The vehicle composition observed at the study sections are shown in Table 2. It is evident that the vehicle compositions at the selected sections were similar and traffic flows at the sections are heterogeneous. 57 to $64 \%$ of the vehicles were motorized two wheelers and 28 to $33 \%$ of the vehicles were cars. Auto rickshaws, light commercial vehicles, buses and other vehicles (mini buses, vans, etc.) formed the rest of the traffic stream. Movement of trucks were restricted during daytime and were not observed during the survey period.

Table 2 Vehicle composition at the study sections

\begin{tabular}{llccccc}
\hline & & \multicolumn{5}{c}{ Composition in Percentage } \\
\cline { 3 - 7 } S1.No & Vehicle Type & \multicolumn{5}{c}{ Location } \\
\cline { 3 - 7 } & & A & B & C & D & E \\
\hline 1 & Car & 33 & 28 & 30 & 26 & 19 \\
2 & Motorised Two Wheeler & 57 & 64 & 62 & 52 & 53 \\
3 & AutoRickshaws & 4 & 3 & 4 & 14 & 20 \\
4 & Light Commercial Vehicle & 2 & 2 & 2 & 2 & 2 \\
5 & Buses & 1 & 1 & 1 & 3 & 4 \\
6 & Others & 2 & 2 & 1 & 3 & 2 \\
\hline
\end{tabular}

At the conventional section, nearly $25 \%$ lane utilization was observed on near side and far side lanes, and the lane utilization was nearly $50 \%$ for the middle lane. Fast moving vehicles, mostly cars, preferred far side lane and slow moving vehicles, mostly motorized two wheelers, preferred the near side lane. On middle lane, it was a mix of motorized two wheelers (57\%) and cars (33\%) with reasonable speed. Table 3 shows the lane wise composition of vehicles at location $\mathrm{A}$. There was a clear pattern that the faster vehicles preferred the far side lane and slower/vulnerable vehicle categories preferred near side lane.

In contrast, at the work zone sections, the lane utilization was almost same on the two available lanes. The cars and motorized two wheelers shared the available space equally on both the lanes.

\section{Analysis of traffic speed}

GPS data of the probe vehicle runs were pre-processed and categorized according to time of the run. The speed profiles of the 88 runs along FSLC (location B) work zone were plotted against their corresponding chainage of the section. Fig. 4 shows the speed-distance plot of GPS data collected at FSLC (location B) work zone.

After the vehicle crossed the Pallavaram intersection (0 chainage) up to 2,250 m chainage the speed was almost constant. There was a reduction in speed in the transition zone (chainage 2,250 to $2,400 \mathrm{~m}$ ), i.e. the section, where the carriageway width of three lanes, was reduced to two lanes. Portion of carriageway, of a lane's width, close to

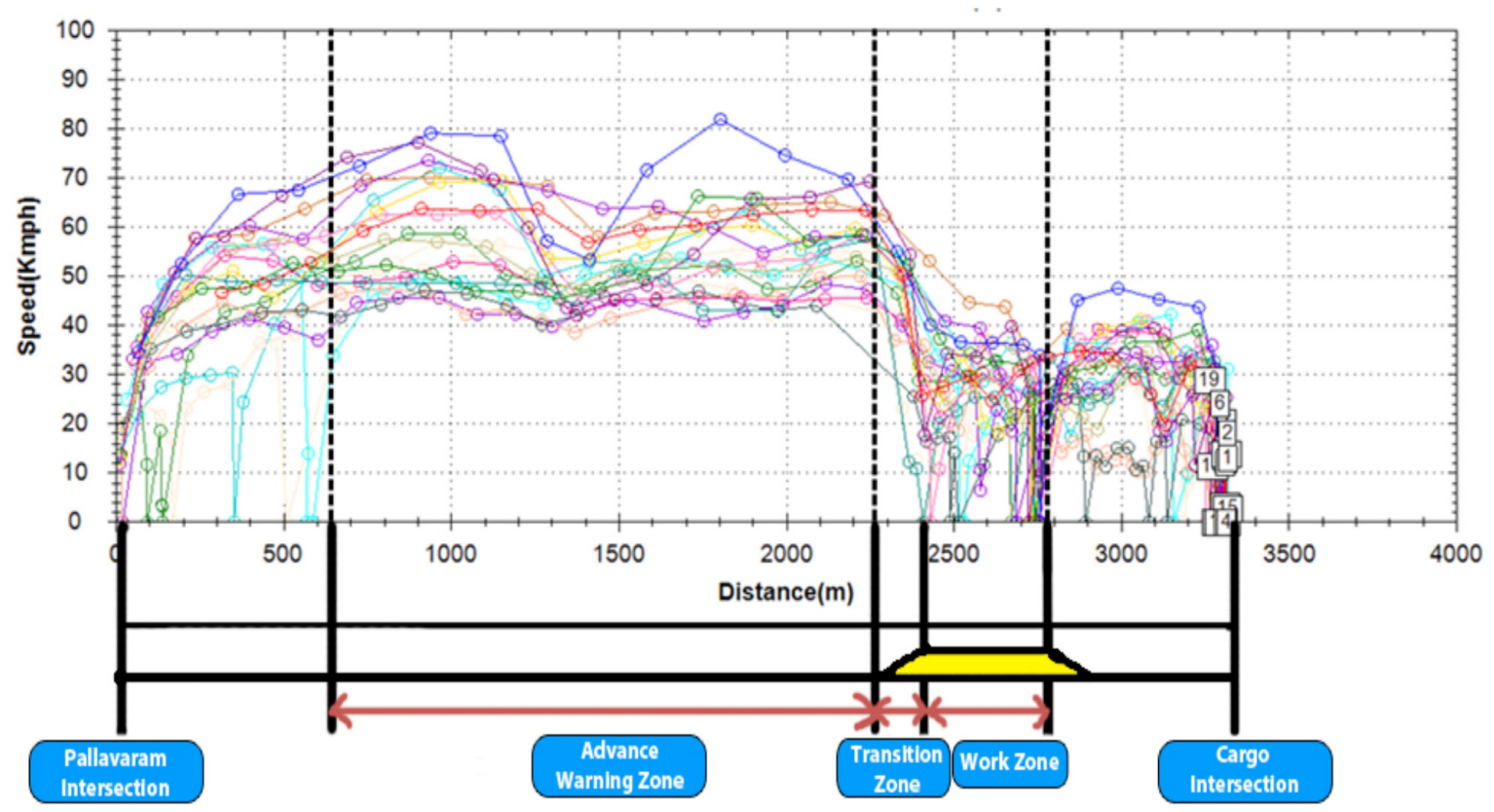

Fig. 4 Speed distance plot of probe vehicles along location B 
Table 3 Lane composition of different vehicle types at location A

\begin{tabular}{|c|c|c|c|c|}
\hline \multirow{2}{*}{$\begin{array}{l}\text { Sl. } \\
\text { No. }\end{array}$} & \multirow{2}{*}{ Vehicle Type } & \multicolumn{3}{|c|}{ Composition in Percentage } \\
\hline & & Lane 1 & Lane 2 & Lane 3 \\
\hline 1 & Auto Rickshaws & 2.7 & 4.8 & 5.9 \\
\hline 2 & $\begin{array}{l}\text { Motorised Two } \\
\text { Wheelers }\end{array}$ & 24.7 & 57.0 & 89.1 \\
\hline 3 & Cars & 64.9 & 32.8 & 2.3 \\
\hline 4 & $\begin{array}{l}\text { Light Commercial } \\
\text { Vehicle }\end{array}$ & 4.1 & 2.0 & 0.7 \\
\hline 5 & Others & 3.7 & 3.5 & 2.0 \\
\hline
\end{tabular}

median (from 2,400 to 2,800 m chainage), was marked as work zone to facilitate construction work. The speed profile of vehicles at work zone (2,400 to 2,800 m) was lesser than the corresponding advance warning zone. Because, the spacing between vehicles got reduced as the vehicles competed with each other to position themselves and move further. Similarly, at NSLC (location C) work zone section, the lane closer to shoulder was marked as work zone (700 to $900 \mathrm{~m}$ chainage) for construction work. A similar pattern of speed variation was observed along the section.

The speed variations at the advance warning zone, transition zone and work zone were obtained from the time space plot of the probe vehicle runs. The speed at the start ( $0 \mathrm{~m}$ chainage) and end $(3,350 \mathrm{~m}$ chainage) of sections were minimal as the vehicle slowed down to take $U$ turns. In the same way, speed variations at other locations were analyzed with the GPS data. The average speed observed at advance warning zone was $53 \mathrm{kmph}$ and it was closer to the average speed measured at the location A. This implies that the traffic flow at the advance warning zone is similar to that as conventional section, i.e., location A. The average speed at the work zone section (location B) was $27 \mathrm{kmph}$, at location $\mathrm{C}$ average speed was $38 \mathrm{kmph}$, and at location D \& E, it was $25 \mathrm{kmph}$ and $23 \mathrm{kmph}$ respectively.

The variation in speed at various work zones from that of advance warning zone is presented in Table 4. It is evident from the analysis that the speed reduction is lesser at location C (NSLC) than that of all other locations.

Majority of cars tend to be on far side on conventional road sections and when the far side lane is closed for construction or other maintenance activities, their speed gets reduced significantly as they try to change lane and find gap between vehicles on middle lane. The speed reduction was maximum at location E, as the entire traffic stream took a diverted/detoured path.

The near side lane is mostly preferred by motorized two wheelers on conventional road sections and when the
Table 4 Speed variation at study sections

\begin{tabular}{lcc}
\hline $\begin{array}{l}\text { Road Section / Work Zone } \\
\text { Types }\end{array}$ & $\begin{array}{c}\text { Average Speed } \\
(\mathrm{kmph})\end{array}$ & $\begin{array}{c}\text { Speed } \\
\text { Reduction (\%) }\end{array}$ \\
\hline $\begin{array}{l}\text { Conventional Section / } \\
\text { Advance Warning Zone }\end{array}$ & 53 & - \\
$\begin{array}{l}\text { Far Side Lane Closure (FSLC) } \\
\text { (Location B) }\end{array}$ & 27 & 49.06 \\
$\begin{array}{l}\text { Near Side Lane Closure } \\
\text { (NSLC) (Location C) }\end{array}$ & 38 & 28.30 \\
$\begin{array}{l}\text { Middle Lane Closure (MLC) } \\
\text { (Location D) }\end{array}$ & 25 & 52.83 \\
Run Around (Location E) & 23 & 56.60 \\
\hline
\end{tabular}

lane is closed for work activities the effort required for the motorized two wheelers to change the lane and identify gap between vehicles on adjacent lane, is relatively less. The reduction in speed at road stretches with work zones on the far side lane was higher than that at the road stretches with work zone on near side lane. At location $\mathrm{D}$, where middle lane was closed, the traffic on middle lane choose the other two lanes and its average speed was significantly less whereas at location $\mathrm{E}$ all vehicles were forced to take a curved path leading to the lowest observed speed.

The variation of stream speed and traffic flow in 5 minutes duration at location B is presented in Fig. 5. The stream speed was low at higher traffic flow and it increased during lower flow levels. The queue formations at the transition zones were observed between 8:15 am and 10:30 am and during this period, the observed stream speed was the lowest when compared to the other time periods. Traffic queue was observed when the traffic flow entering the work zone section had exceeded the capacity of the work zone section.

\section{Capacity analysis of the sections}

The hourly flow rate was computed in PCEs/hr with the 5 minutes flow observed and stream speed was computed as the harmonic average of the observed vehicle speeds in the corresponding 5 minutes interval. The flow rate and speed of the traffic stream were used to estimate the capacity of the study sections using Van Aerde's method (Van Aerde and Rakha, 1995) and Maze's method (Maze et al., 2000).

Capacity of the conventional sections similar to location A, i.e. for one direction of six lane divided road, carrying heterogeneous traffic, has been reported as 5,900 PCEs/ hour (Gunasekaran et al., 2015) to 6,100 PCEs/hour (Dhamaniya and Chandra, 2014). In this study, for analysis, 5,900 PCEs/hour has been considered as the capacity for one direction of six lane divided conventional road sections. 


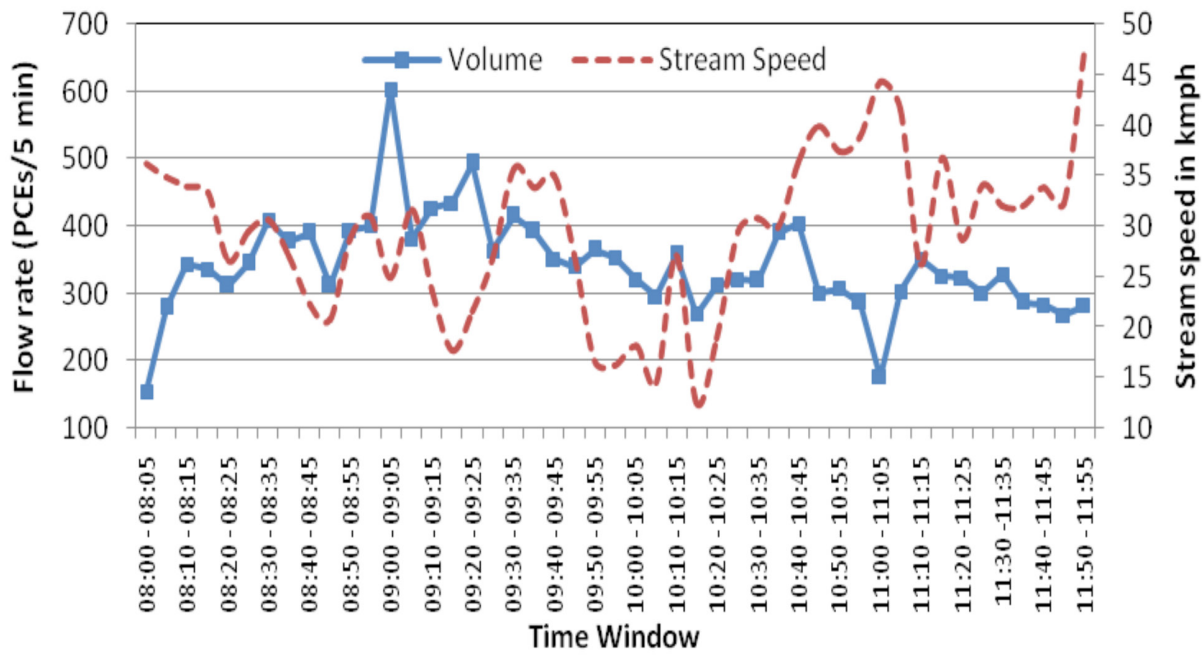

Fig. 5 Flow rate and stream speed variation at location B

The speed - density and speed - flow relationships for location B, obtained using Van Aerde's method (Van Aerde and Rakha, 1995), are shown in Fig. 6 and Fig. 7 respectively. The speed - flow plot (Fig. 7) indicates that at work zone during the period of queue formation, i.e. peak flow period, congestion exists. The capacity of the road section at location B was estimated at 4,400 PCEs/hour by Van Aerde's method (Van Aerde and Rakha, 1995).

As suggested by Maze et al. (2000) the capacity at the work zone is the average of the ten highest values observed before and after the queue formation. The formation of queue was observed when the flow rate was high and the corresponding speed was low. The duration of queue formation and the corresponding highest flow rates were obtained from the Fig. 5. The capacity of location B by Maze's method (Maze et al., 2000) as 5,247 PCEs/hour.

Similar to location B, data collected from all other work zones were analyzed to estimate the capacity using Van Aerde's method (Van Aerde and Rakha, 1995) and Maze's method(Maze et al., 2000). The capacity values obtained for all the work zone sections by both methods are tabulated in Table 5.

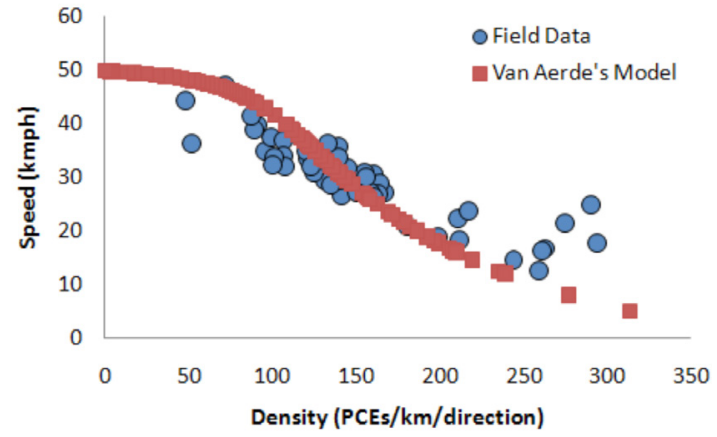

Fig. 6 Speed - density relationship of traffic flow at location B

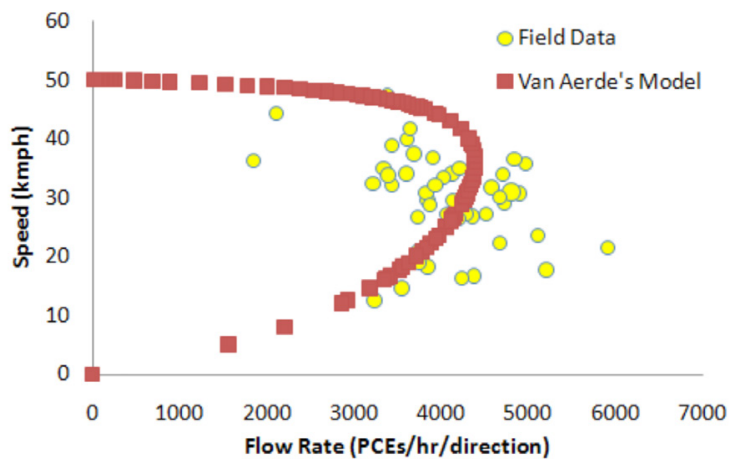

Fig. 7 Speed - flow relationship of traffic flow at location B

Table 5 Comparison of estimated capacity values

\begin{tabular}{lccc}
\hline Work Zone Type & $\begin{array}{c}\text { Van Aerde's method } \\
\text { (Van Aerde and Rakha, 1995) } \\
\text { (PCUs/hr/direction) }\end{array}$ & $\begin{array}{c}\text { Maze's method } \\
\text { (Maze et al., 2000) } \\
\text { (PCUs/hr/direction) }\end{array}$ & $\begin{array}{c}\text { Difference } \\
\text { (\%) }\end{array}$ \\
\hline $\begin{array}{l}\text { Far Side Lane Closure } \\
\text { (Location B) }\end{array}$ & 4,400 & 5,247 & 16.1 \\
$\begin{array}{l}\text { Near Side Lane Closure } \\
\text { (Location C) }\end{array}$ & 5,000 & 5,853 & 14.5 \\
$\begin{array}{l}\text { Middle Lane Closure } \\
\text { (Location D) }\end{array}$ & 4,000 & 4,183 & 4.37 \\
$\begin{array}{l}\text { Run Around } \\
\text { (Location E) }\end{array}$ & 3,200 & 2,795 & 14.49 \\
\hline
\end{tabular}




\section{Discussion of results}

The capacity values of the work zones, estimated by Maze's method (Maze et al., 2000) and Van Aerde's method (Van Aerde and Rakha, 1995) were found to be closer. The difference of capacity values, obtained by the two methods, varied from $4 \%$ to $16 \%$ at the selected work zones. However, the capacity value estimated using Van Aerde's method (Van Aerde and Rakha, 1995) is considered to be more realistic than Maze's method (Maze et al., 2000). Because in Maze's method (Maze et al., 2000), the capacity of the work zone is computed with flow rates observed after queue formation also. This tends the capacity estimation to be underestimated, as the flow rate may be lesser than the capacity value in the congested traffic state. Another reason for inconsistency of Maze's method (Maze et al., 2000) is that on Indian roads, the motorized two wheelers manage to sneak between the larger vehicles in the event of queue formations and the length of queue is highly volatile. The high composition of motorized two wheelers (about $60 \%$ ) increases the probability of queue lengths to vary dynamically.

Introduction of work zone reduces the carriageway width available for the traffic movement and thereby reduces the capacity of the road section. The estimated capacity values of the conventional section and different types of work zone sections are tabulated in Table 6. In the selected work zone sections, the carriageway width is reduced to 2 lanes from 3 lanes, but the capacity varied when larger vehicles changed their lanes and when all vehicles traversed a curved path.

From the Table 4 and Table 6, it is evident that the capacity reductions at various work zones had good correlation with the speed reductions at the respective work zones. The speed reductions were due to the configuration of the work zone. The highest capacity reduction of about $46 \%$ at location $\mathrm{E}$ was due to the motion of all vehicles on a curved path and reduction in speed at that location was also highest. There seems to be defined pattern of lane selection in heterogeneous traffic flow in midblock

Table 6 Capacity reduction at work zones

\begin{tabular}{lcc}
\hline Location & $\begin{array}{c}\text { Capacity } \\
\text { (PCEs/hr/direction) }\end{array}$ & $\begin{array}{c}\text { Capacity Reduction } \\
(\%)\end{array}$ \\
\hline Location A & 5,900 & - \\
Location B & 4,400 & 25.42 \\
Location C & 5,000 & 15.25 \\
Location D & 4,000 & 32.20 \\
Location E & 3,200 & 45.76 \\
\hline
\end{tabular}

sections. Smaller vehicles (or vulnerable vehicles) move at lower speed and choose near side lane whereas larger vehicles (safer vehicles) move at higher speed and prefer far side lane in the midblock sections. When the work zone obstruction is on near side lane, the overall speed reduction is lesser and it increases when the larger vehicles are diverted from far side lanes.

\section{Conclusion}

The reduction in capacity, due to the lane closure, on the road segments carrying homogeneous traffic is proportionate to the reduced width of the carriageway. The configuration of the work zone plays an important role in the capacity of the work zone section. But, on the road segments carrying heterogeneous traffic, capacity is found to vary with width of lane closure and with lane that is closed for traffic.

The RA work zone resulted in higher reduction in stream speed and capacity, as all the lanes of the work zone is closed for work activities and the traffic is diverted on a curved path. Thus, this type of work zone causes speed drop to the vehicles on all the 3 lanes. In location D, MLC work zone, the traffic of the middle lane is disturbed. Hence the traffic on middle lane changes lane and disturbs the traffic of both far side and near side lanes. In contrast to these two work zones, the capacity reduction is lesser for work zone types at location B and C. Due to the far side lane closure, the traffic of far side lane, especially cars which are predominant at far side lane, are forced to change their lane. It creates more disturbances to the flow on middle lane. But, the closure of near side lane forced the motorized two wheelers, which is predominant in near side lane, to change their lane to middle lane, creating lesser disturbance to the flow as the motorized two wheelers are of relatively smaller size and have better maneuverability. The $25 \%$ reduction in capacity at FSLC over the $15 \%$ capacity reduction at NSLC was attributed to the higher speed of vehicles at far side lane, i.e., cars, when compared to the speed of vehicles at near side lane.

As far as the application of this study to the planners is concerned, this study is highly helpful in making decisions on which type of work zone is to be adopted at a location where vehicular composition and driving behavior are similar to the study sections. Alternate plans of work zones can be evaluated by several parameters such as number of lanes to be reserved for construction activities, duration of lane closures, delay caused to the road users and economic loss during the period of lane restrictions. 
This study can support the policy decisions on selection of work zone plan among the group of alternatives that minimizes the travel speed reduction and delay caused to the road users.

\section{References}

Chandra, S., Kumar, V., Sikdar, P. K. (1995) "Dynamic PCU and Estimation of Capacity of Urban Roads", Journal of Indian Highways, 23(4), pp. 17-28.

Dhamaniya, A., Chandra, S. (2014) "Midblock Capacity of Urban Arterials Roads in India", Journal of Indian Highways, 42(7), pp. $45-57$.

Elangovan, E., Gladson, D. J., Gunasekaran, K., Kalaanidhi, S., Karthiga, K. (2015) "Study on Traffic Flow Characteristics using Probe Vehicles", In: Proceedings of 14th International Conference on Computers in Urban Planning and Urban Management, Boston, MA, USA, Article number: 151. [online] Available at: http://web. mit.edu/cron/project/CUPUM2015/proceedings/Content/analytics/151_elangovan_h.pdf [Accessed: 12 October 2015]

Greenshields, B. D., Bibbins, J. R., Channing, W. S., Miller, H. H. (1935) "A study of traffic capacity", Proceedings of Highway Capacity Research, 14(1), pp. 448-477.

Gunasekaran, K., Kalaanidhi, S., Gayathri, H., Velmurugan, S. (2015) "A Concept of Platoon Flow Duration in Data Aggregation for Urban Road Capacity Estimation", In: 14th International Conference on Computers in Urban Planning and Urban Management, Boston, MA, USA, Article number: 166. [online] Available at: http://web.mit.edu/cron/project/CUPUM2015/proceedings/Content/model-ing/166_karuppanan_h.pdf [Accessed: 15 October 2015]

Heaslip, K., Jain, M., Elefteriadou, L. (2011) "Estimation of arterial work zone capacity using simulation", Transportation Letters: The International Journal of Transportation Research, 3(2), pp. 123-134. https://doi.org/10.3328/TL.2011.03.02.123-134

Jiang, Y., Li, S. (2002) "Measuring and analyzing vehicle position and speed data at work zones using global positioning system", Ite Journal, 72(3), pp. 48-53.

Knoop, V., Hoogendoorn, S., Adams, K. (2009) "Capacity reductions at incident sites on motorways", European Journal of Transport and Infrastructure Research, 9(4), pp. 10363-10379. [online] Available at: http://resolver.tudelft.nl/uuid:219eb236-8f89-4d91b1ce- c280f64ea1a4 [Accessed: 01 May 2016]

Maze, T. H., Schrock, S. D., Kamyab, A. (2000) "Capacity of Freeway Work Zone Lane Closures", In: Mid-Continent Transportation Symposium Proceedings, Iowa State University, Ames, IA, USA, pp. $178-183$

\section{Acknowledgment}

The authors are grateful to Centre of Excellence in Urban Transport, Indian Institute of Technology Madras (CoEUT, IITM) for their financial support for the research study "Study on Safety at Work Zones in Urban Areas".

Pipes, L.A. (1953) "An Operational Analysis of Traffic Dynamics", AIP Journal of Applied Physics, 24(3), pp. 274-281. https://doi.org/10.1063/1.1721265

Porter, R. J., Wood, J. S. (2013) "Exploring endogeneity of macroscopicspeed parameters: empirical study during low volume conditions in construction work zones", Transportation Letters: The International Journal of Transportation Research, 5(1), pp. 27-37. https://doi.org/10.1179/1942786712Z.0000000004

Rakha, H. (2009) "Validation of Van Aerde's simplified steady state car-following and traffic stream model", Transportation Letters: The International Journal of Transportation Research, 1(3), pp. 227-244. https://doi.org/10.3328/TL.2009.01.03.227-244

Sanuallah, I., Quddus, M. A., Enoch, M. P. (2013) "Estimating Link Travel Time from Low-frequency GPS Data", In: Transportation Research Board 92nd Annual Meeting, Washington, DC, USA, Article number: 13-3909. [online] Available at: https://rid.trb.org/ view/1242269 [Accessed: 25 February 2017]

Van Aerde, M. (1995) "Single regime speed-flow-density relationship for congested and uncongested highways", In: 74th Annual Meeting of the Transportation Research Board, Washington DC, USA, Paper no. 95080, January, 22-28, 1995.

Van Aerde, M., Rakha, H. (1995) "Multivariate Calibration of Single Regime Speed-Flow-Density Relationships", In: Pacific Rim Trans Tech Conference.1995 Vehicle Navigation and Information Systems Conference Proceedings. 6th International VNIS. A Ride into the Future, Seattle, WA, USA, pp. 334-341. https://doi.org/10.1109/VNIS.1995.518858

Vidya, R., Santhakumar, S. M., Mathew, S. (2012) "Impact of work zones on speed variation during widening of the highway - a case study", International Journal of Engineering Science and Technology (IJEST), 4(2), pp. 546-554. [online] Available at: http://www. idc-online.com/technical_references/pdfs/civil_engineering/ Impact_Of_Work_Zones\%20.pdf [Accessed: 21 June 2014]

Wasson, J. S., Young, S. E., Sturdevant, J., Tarnoff, P. J., Ernst, J. M., Bullock, D. M. (2008) "Evaluation of Special Event Traffic Management: The Brickyard 400 Case Study", Joint Transportation Research Program Other Publications and Reports, Purdue University, West Lafayette, IN, USA, TRB Paper 09-1730. https://doi.org/10.5703/1288284314673 